\title{
On the Mechanism of Dissolution Inhibition in Phenolic Resins
}

\author{
Chen-Chy Lin, Tung-Feng Yeh and Arnost Reiser \\ Institute of Imaging Sciences, Polytechnic University \\ Brooklyn NY 11201 \\ Kenji Honda and Bernard T. Beauchemin \\ OCG Microelectronic Materials, Inc. \\ East Providence RI 02914
}

Until quite recently it was believed that dissolution inhibition in phenolic resins is based on a general hydrophobic effect of the inhibitor. Honda et al. [5] have now shown that the hydrophobicity of an additive is not sufficient and that the polar functional groups of the inhibitor play an important role in the inhibition effect. They found that additives with very similar skeletal structures, and therefore with similar hydrophobicity, but which differ in their polar functional groups, have very different inhibition efficiencies in a common novolak resin. In an earlier communication [4] it was suggested that inhibition in phenolic resins comes about by the blocking of some of the hydrophilic $\mathrm{OH}$-groups. Such blocking action by the inhibitor presupposes interaction between the inhibitor and the phenols of the resin. Here we investigate this interaction by determining the associated equilibrium constants in dilute solution. From these data the fraction of phenol-bound inhibitors in the casting solutions of the films can be estimated. For the group of additives investigated by Honda et al. [5] the fraction of phenol-bound inhibitors correlates quite satisfactorily with the inhibition cffect. 


\section{Introduction}

A whole class of positive working photoresists is based on the inhibition of novolak dissolution by various light sensitive additives, in particular by derivatives of naphthodiazoquinone. Because of the importance of these resists for the semiconductor device industry they have attracted considerable interest, and several mechanism for the inhibition of novolak dissollution have been advanced. According to one [1], diazoquinones inhibit dissolution by coupling with the para position of the phenolic moieties of the resin. Others [2,3] cite the enrichment of the hydrophobic inhibitor at the surface of the dissolving film as the cause of inhibition.

In a recent communication [4] a model of novolak dissolution was presented, based on the realization that novolak is an amphiphilic material which contains hydrophilic as well as hydrophobic components. In fact, a novolak film may be regarded as a hydrophobic solid in which hydrophilic sites, the OH-groups of the phenols, are embedded. When such a film is immersed in an alkaline developer, base is attracted to the hydrophilic sites and repelled by the hydrophobic regions of the medium. As a result, it migrates into the matrix by a succession of transfers or jumps from one hydrophilic site to the next, a process that has been termed "percolative diffusion".

When base encounters a phenol group in the matrix, it transforms the phenol into a phenolate ion pair.

$$
\mathrm{POH}+\mathrm{K}^{+} \mathrm{OH}^{-} \mathrm{PO}^{+} \mathrm{K}^{+}+\mathrm{H}_{2} \mathrm{O}
$$

This deprotonation reaction is a precondition for dissolution; its progress in the matrix depends on the rate of supply of base to the phenolic centers. The rate of dissolution is thus controlled by the rate of percolative diffusion of base through the solid resin.

In the process of percolative diffusion the phenol groups and, at a later stage, the equally hydrophilic phenolate sites act as stepping stones in the migration of base into the film, and the rate of dissolution depends critically on the density of hydrophilic sites. Any intervention into the system which reduces the number or the accesibility of the hydrophilic sites will lower the dissolution rate. We believe that the inhibitor functions by eliminating hydroxylic sites from the percolation field of the resin. To do this, the inhibitor must have two essentiel attributes: 
a) It must carry a polar "anchor" group which is capable of interacting with phenol and which actually locates the inhibitor at one of the hydrophilic sites.

b) It must have a sufficiently large hydrophobic body to shield the percolation site from the approaching base.

To demonstrate the effect of the anchor group on the inhibition efficiency of an additive, Honda et al. [5] investigated five potential inhibitors of very similar hydrophobic structure, but with different anchor groups. These are shown as items 1 to 5 in Scheme I.

\section{Scheme I}

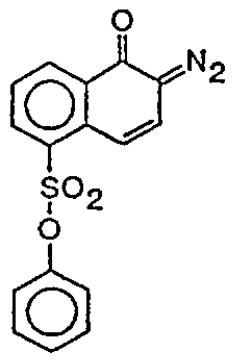

1

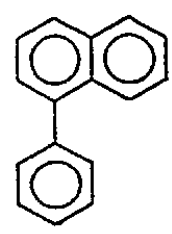

5

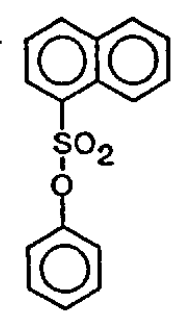

2<smiles>N=C1C=Cc2ccccc2C1=O</smiles>

6

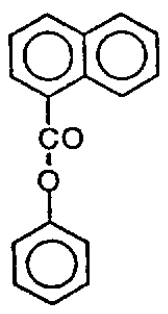

3

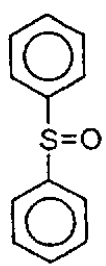

7

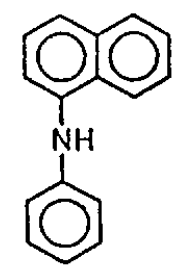

4

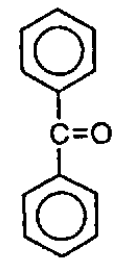

8

Honda et al. found considerable differences in the inhibition efficiency of these molecules when added in equivalent quantities to a standard novolak resin. In light of the above hypothesis of inhibitor action these differences were thought to be caused by differences in the number of phenol sites eliminated by the inhibitor, i.e. by differences in the binding efficiency of different anchor groups with respect to phenol. In this communication we report on a correlation between the fraction of phenol-bound inhibitor molecules and the strength of the inhibition effect in the group of additives initially investigated by Honda et al. [5]. 


\section{Equilibrium Constants of Phenol-Acceptor Interaction}

It would be ideal if the fraction of bound and of free anchor (acceptor) groups could be determined directly in the solid novolak film. However, spectroscopic analysis of solid resin films is not straightforward. It was thought, therefore, that a first approach to the problem could be made by calculating the fraction of bound acceptor groups from the equilibrium constant of the association reaction as determined in dilute solution.

In the more concentrated casting solutions of the films, the acceptor groups of the inhibitors compete for the phenolic $\mathrm{H}$-bond with other phenols. The situation is described by the simultaneous equations of coupled equilibria.

$$
\begin{aligned}
& \mathrm{P}+\mathrm{A}=\mathrm{PA} \\
& \mathrm{P}+\mathrm{P}=\mathrm{P}_{2}
\end{aligned}
$$

where $\mathrm{P}$ and $\mathrm{A}$ stand for phenol and for the acceptor, $\mathrm{PA}$ is the hydrogen- bonded complex and $\mathrm{P}_{2}$ is a phenol dimer, the result of the self-association of phenol in solution.

The equilibrium constants of (1) and (2) are given by

$$
\begin{gathered}
K_{A}=\frac{[P A]}{[P][A]} \\
K_{P}=\frac{\left[P_{2}\right]}{[P]^{2}}
\end{gathered}
$$

where the bracketts indicate equilibrium concentrations.

The equilibrium constants were determined in dilute $\mathrm{CCl}_{4}$ solution by monitoring the spectra of model phenols in the presence of increasing concentrations of the acceptor. The concentration of the complexes [PA] in eq 3 was expressed as the difference between the overall nominal concentration of phenol $[\mathrm{P}]_{\mathrm{o}}$ and the equilibrium concentration $[\mathrm{P}]$ of free phenol.

$$
\mathrm{K}_{\mathrm{A}}=\frac{[\mathrm{P}]_{0}-[\mathrm{P}]}{[\mathrm{P}]\left([\mathrm{A}]_{0}-[\mathrm{P}]_{0}+[\mathrm{P}]\right)}
$$

The value of $[\mathrm{P}]$ was estimated from the intensity of the $\mathrm{OH}$-stretching vibration of phenol at 3600 $\mathrm{cm}^{-1}$. Lambert's and Beer's law was found to be strictly obeyed in the dilute solutions. The equilibrium constants of the interaction of unsubstituted phenol with the five inhibitors of Honda's 
study and with a few other inhibitors are listed in Table I.

Table I

Equilibrium Constants for the Interaction between Phenol and a Group of Inhibitors

Acceptor

$\mathbf{K}_{\mathbf{A}}$

\begin{tabular}{llc}
1 & 2,1-Naphthodiazoquinone-5-phenylsulfone & 36.7 \\
2 & Naphthalene-1-sulfonic acid phenylester & 3.37 \\
3 & 1-Naphthalene carboxylic acid phenylester & 2.5 \\
4 & 2-Phenylaminonaphthalene & 1.35 \\
5 & 1-Phenylnaphthalene & 0.3 \\
6 & 2-Diazo-1-naphthoquinone & 21.9 \\
7 & Diphenylsulfoxide & 52 \\
8 & Benzophenone & 6.47 \\
\hline
\end{tabular}

The equilibrium constant of the self-association of phenol was determined from the dependence of the free phenol peak on the overall phenol concentration $[\mathrm{P}]_{0}$ by comparison with the Lambert-Beer law. (See Figure 1). For the case of phenol in $\mathrm{CCl}_{4}$ a value of $\mathrm{K}_{\mathrm{p}}=3.1$ was found; for o-cresol that value was 2.5 .

The phenol groups in novolak and other phenolic resins are sterically hindred to a considerable degree. It was thought advisable to take account of this effect in estimating phenol-inhibitor interactions. To explore the effect of steric hindrance we have determined the equilibrium constants for the inhibitors of Scheme I with a number of ortho-substituted model phenols. The equilibrium constants are collected in Table II. The data show that steric hindrance affects strong hydrogen bonds more than weak ones. In the strong bonds of the acceptors 1, 6 and 7, donor and acceptor are drawn near together and, in that situation, ortho-substituents have a more pronounced effect on the intensity of interaction than in the case of the more distant bonds of acceptors 2, 3, 4 and 5 . Furthermore, the nominal size of the ortho-substituent does not seem to matter very much, while two ortho-substituents have a much larger effect than one. 


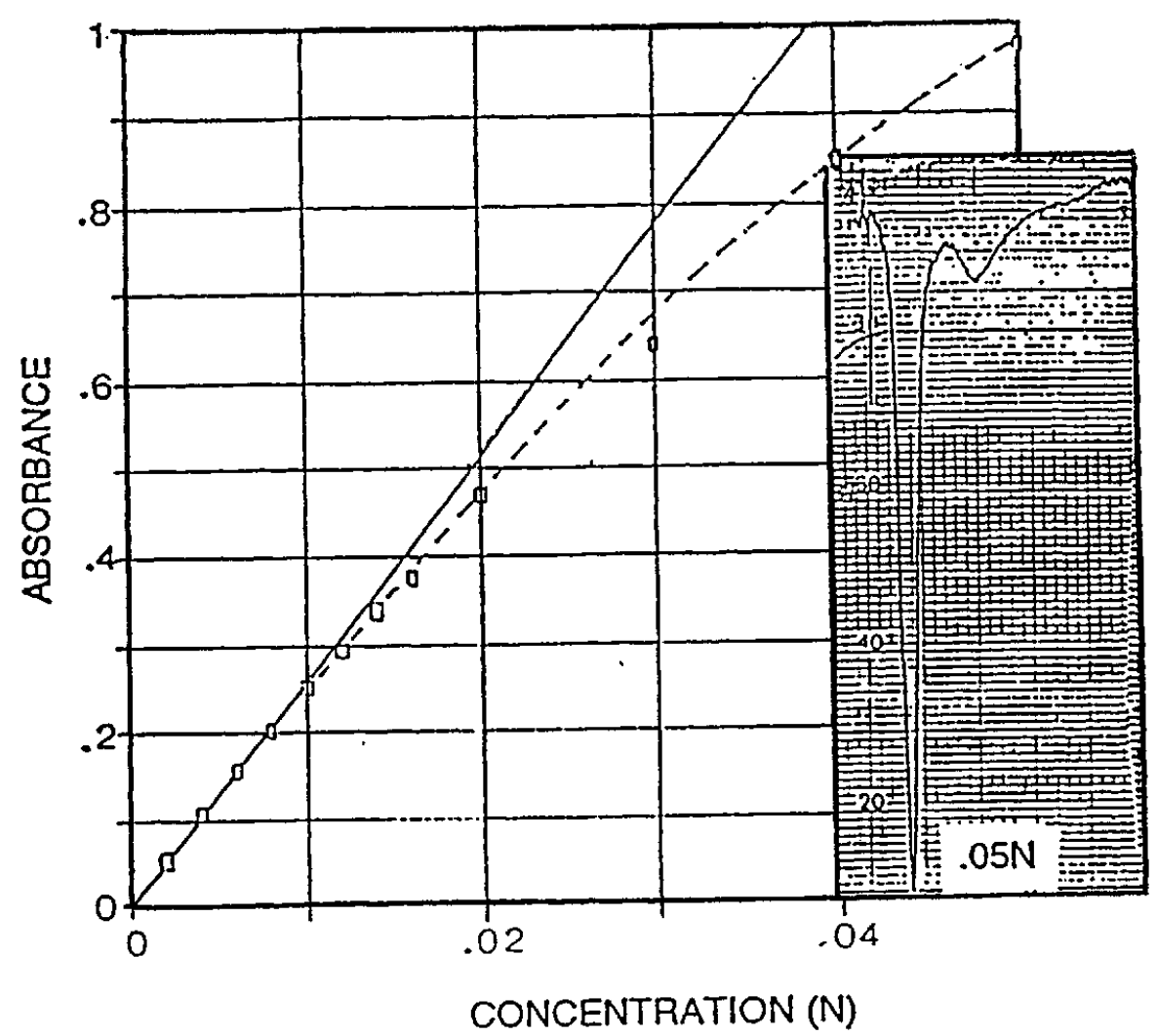

Figure 1. Determining the self-association constant $\mathrm{K}_{\mathrm{p}}$ via the deviations of the phenol absorption at $3600 \mathrm{~cm}^{-1}$ from the Lambert-Beer law.

Table II

Effect of Steric Hindrance on the Phenol-Acceptor Interaction Equilibrium Constants

Acceptor Phenol 2-Methyl 2-Ethyl 2-Isopropyl 2,6-Dimethyl

\begin{tabular}{cccccc}
\hline 1 & 37 & 14 & 13 & 10 & 6 \\
2 & 3.4 & 3.2 & 2.3 & 2.8 & 1.7 \\
3 & 2.5 & 2.2 & 2.1 & 2.2 & 1.4 \\
4 & 1.4 & 1.3 & 1.1 & 1.1 & 0.91 \\
5 & 0.3 & 0.6 & 0.6 & 0.5 & 0.5 \\
6 & 22 & 15 & 15 & 15 & 5.8 \\
7 & 52 & 29 & 28 & 28 & 8.4 \\
8 & 6.5 & 4.3 & 4.1 & 4.3 & 2.2 \\
\hline
\end{tabular}




\section{Monitoring the Acceptor Spectrum}

At the point of casting in solution as well as in the solid matrix, the acceptor finds itself surrounded by a large excess of phenol groups. In that situation it is not practical to monitor changes of phenol absorption, rather it is necessary to focus on the spectrum of the acceptor.

Figure 2 illustrates a viable procedure. It refers to solution of inhibitor 2 in Scheme I. Trace (a) of the Figure shows part of the spectrum of a $0.01 \mathrm{M}$ solution of inhibitor 2 in $\mathrm{CCl}_{4}$. The absorption bands at 1382 and at $1365 \mathrm{~cm}^{-1}$ belong to the $\mathrm{S}=\mathrm{O}$ stretching vibration of the free acceptor. Trace (b) shows the same spectrum in the presence of $0.1 \mathrm{M}$ phenol, trace (c) the same in the presence of $0.2 \mathrm{M}$ phenol. The relevant phenol spectrum has been subtracted from the experimental traces. It can be seen that a new band is growing in at $1372 \mathrm{~cm}^{-1}$ which corresponds to the associate between the inhibitor and phenol and which therefore monitors the rise of the concentration of bound acceptor.

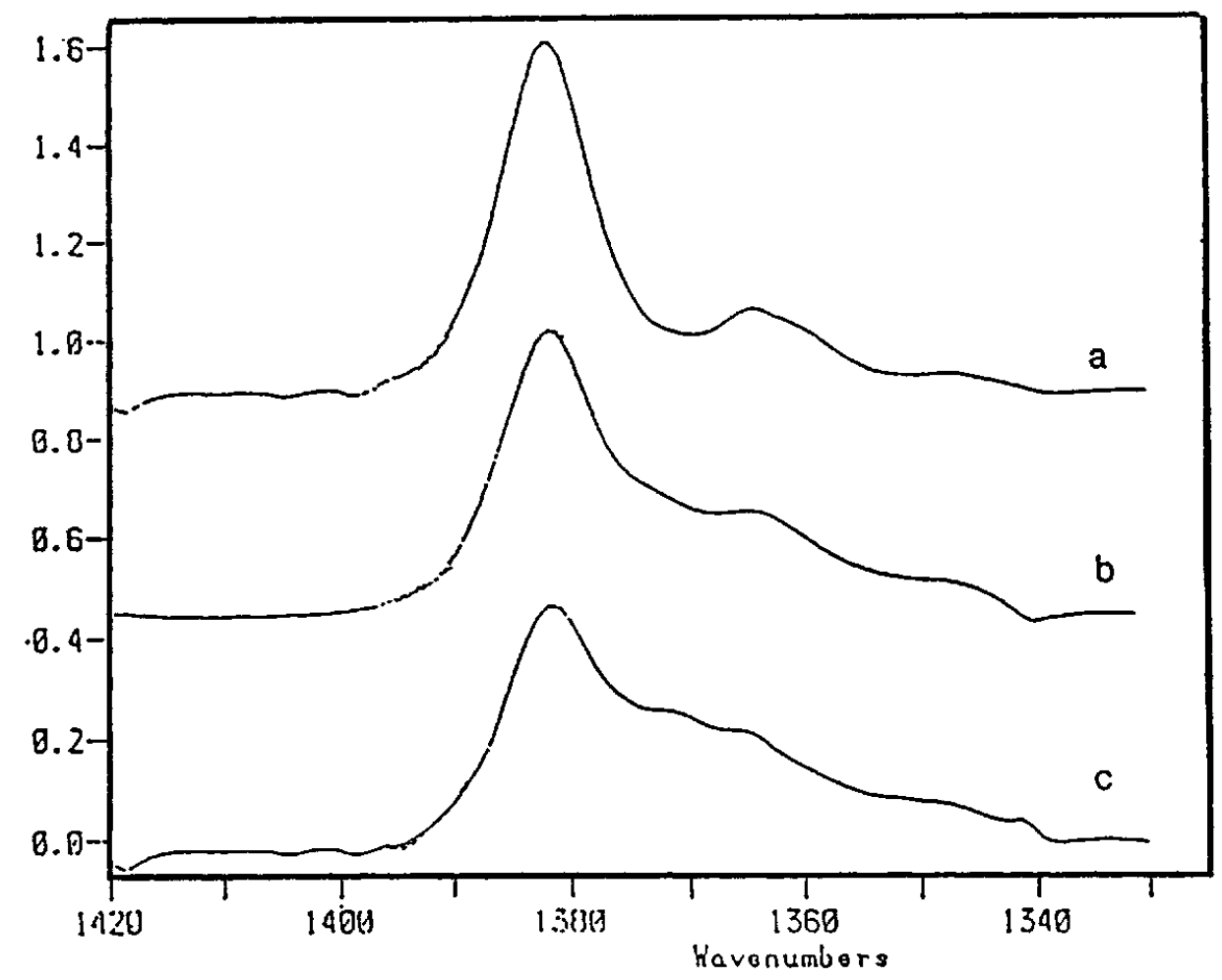

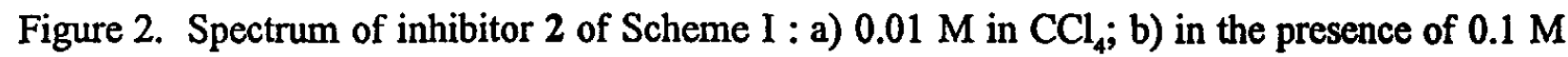
phenol; $\mathrm{c}$ ) in the presence of $0.2 \mathrm{M}$ phenol. The spectrum of phenol was subtracted from the traces' 
As a test of the success of this deconvolution procedure we have calculated the equilibrium constants for the acceptor-phenol interaction from the data. The equilibrium constant of eq 3 is now expressed in terms of the overall concentration of acceptor $[\mathrm{A}]_{\mathrm{o}}$ and and the concentration of free acceptor $[\mathrm{A}]$.

$$
\mathrm{K}_{\mathrm{A}}=\frac{[\mathrm{A}] \mathrm{o}-[\mathrm{A}]}{[\mathrm{A}]\left([\mathrm{P}]_{\mathrm{o}}-[\mathrm{A}] \mathrm{o}+[\mathrm{A}]\right)}
$$

These determinations were carried out for the acceptors 2, 6 and 8 . Table III compares the values obtained in that way with those which were obtained by monitoring free phenol. The agreement is not perfect, but it does give some modest confidence in the possibility of deriving free and bound acceptor concentrations from spectral measurements in polymer matrices.

\section{Table III}

Equilibrium Constants obtained in Dilute Solution Monitoring the Inhibitor, and Monitoring Phenol

Acceptor from acceptor spectr. from phenol spectr.

\begin{tabular}{lcc}
\hline 2 & 2.7 & 3.4 \\
6 & 20.6 & 21.9 \\
8 & 8.2 & 6.5 \\
\hline
\end{tabular}

\section{Calculating the Fraction of Phenol-Bound Inhibitor}

The fraction of bound inhibitor is defined by the expression

$$
x=\frac{[\mathrm{PA}]}{[\mathrm{A}]_{0}}=\frac{[\mathrm{PA}]}{[\mathrm{PA}]+[\mathrm{A}]}
$$

Using eqs 3 and 4 and the stoichiometric relations of (1) and (2) the fraction $[\mathrm{PA}] /[\mathrm{A}]=\mathrm{x}$ can be expressed in terms of the equilibrium constants and the overall concentration of phenol: 


$$
x=\frac{\left(K_{A} / K_{p}\right) B}{\left.1+K_{A} / K_{P}\right) B}
$$

where B stands for the expression

$$
\mathrm{B}=0.25\left\{\left(1+8 \mathrm{~K}_{\mathrm{p}}\left([\mathrm{P}]_{0}-\mathrm{x}[\mathrm{A}]_{0}\right)\right)^{1 / 2}-1\right\}
$$

Equation (8) cannot be made entirely explicit in $\mathrm{x}$, because the fraction of bound inhibitor appears also in the expression for B. The fraction of bound inhibitor must, therefore, be calculated by a series of iterations, until the values of $x$ stabilize. Figure 3 shows the fraction of phenol-bound inhibitor as a function of phenol concentration for an initiator concentration of $[\mathrm{A}]_{0}=0.25 \mathrm{M}$ and a self-association constant of the $\mathrm{OH}$-groups of the resins of $\mathrm{K}_{\mathrm{p}}=2.5$ and for the values of the equilibrium constant $\mathrm{K}_{\mathrm{A}}$ indicated in the Figure.

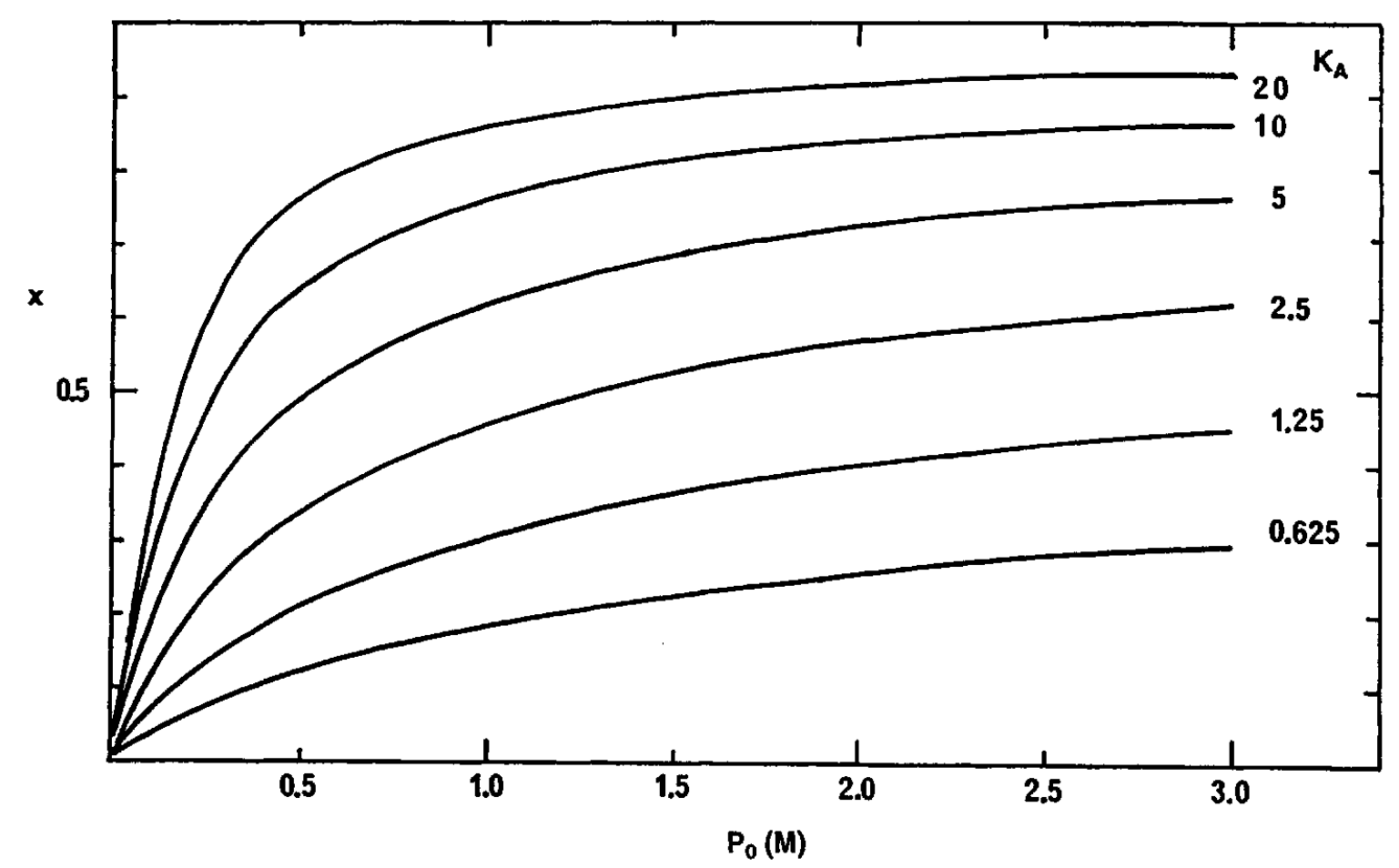

Figure 3. Fraction of phenol-bound inhibitor as a function of the phenol concentration calculated for a number of values of $\mathrm{K}_{\mathrm{A}}$ and for $[\mathrm{A}]_{\mathrm{o}}=0.25 \mathrm{M}$ and $\mathrm{K}_{\mathrm{p}}=2.5$. 
In calculating the fraction of phenol-bound inhibitor in the matrix it is assumed that the distribution of components in the solution at the casting point will be replicated in the solid film. Following some qualitative experiments we have estimated that the phenol concentration at the casting point is $3 \mathrm{M}$, which corresponds to a solid content of $40 \%$. For inhibitor 2 of Scheme I where $\mathrm{K}_{\mathrm{A}}=3.2$ and where we assume a value of the self-association constant of $\mathrm{K}_{\mathrm{P}}=2.5$ equation (8) leads to a value of $x=0.67$ for the fraction of phenol-bound inhibitor. The data obtained in this way for the other inhibitors of Honda's study are listed in Table IV.

It can be seen in Figure 3 that because of the competition between the acceptor-phenol reaction with the self-association of phenol the slopes of the $\mathbf{x}\left(\mathrm{P}_{\mathbf{0}}\right)$ curves are quite shallow above a phenol concentration of $2 \mathrm{M}$. This means that the phenol concentration at casting point has only a moderate effect on the value of $x$ and need not be known too accurately. on the value of $x$.

\section{Direct Observation of the Bound Fraction of Inhibitor}

The calculation of the fraction of bound inhibitor at casting point is based on equilibrium constants that were measured in very dilute solutions. This assumes the constancy of $K_{A}$ and of $K_{P}$ over a wide concentration range. To check the validity of this assumption we have tried to determine the fraction of bound inhibitor directly from the IR spectrum in solid films of phenolic resins. In order to be able to modulate the contents of free phenol in these experiments we have used four partially methylated samples of poly(vinylphenol) [4] containing $2,5,15$ and $21 \mathrm{~mol} \%$ of free $\mathrm{OH}-$ groups. Benzophenone was chosen as the acceptor (inhibitor) because the stretching vibration of its $\mathrm{C}=\mathrm{O}$ group at $1650 \mathrm{~cm}^{-1}$ falls well outside the IR absorption of phenol. Figure 4 shows the relevant region of the spectrum of benzophenone dissolved in films of the four resins.

The films were baked at $100^{\circ}$ for 30 minutes whereby a part of the benzophenone evaporated, but the concentration $[A]_{0}$ of benzophenone remaining in the film could be estimated from the overall intensity of the benzophenone absorption. The fractions of free and of phenol-bound benzophenone were derived from the intensity of the "free" and "bound" bands at 1652 and 1646 $\mathrm{cm}^{-1}$ respectively. The data are collected in Table IV. Values of $\mathrm{x}$ were also calculated via equations (8) and (9) for $K_{A}=5.0$ and $K_{P}=2.5$ and these were used to draw the $x\left(P_{\circ}\right)$ curve in Figure 5. 


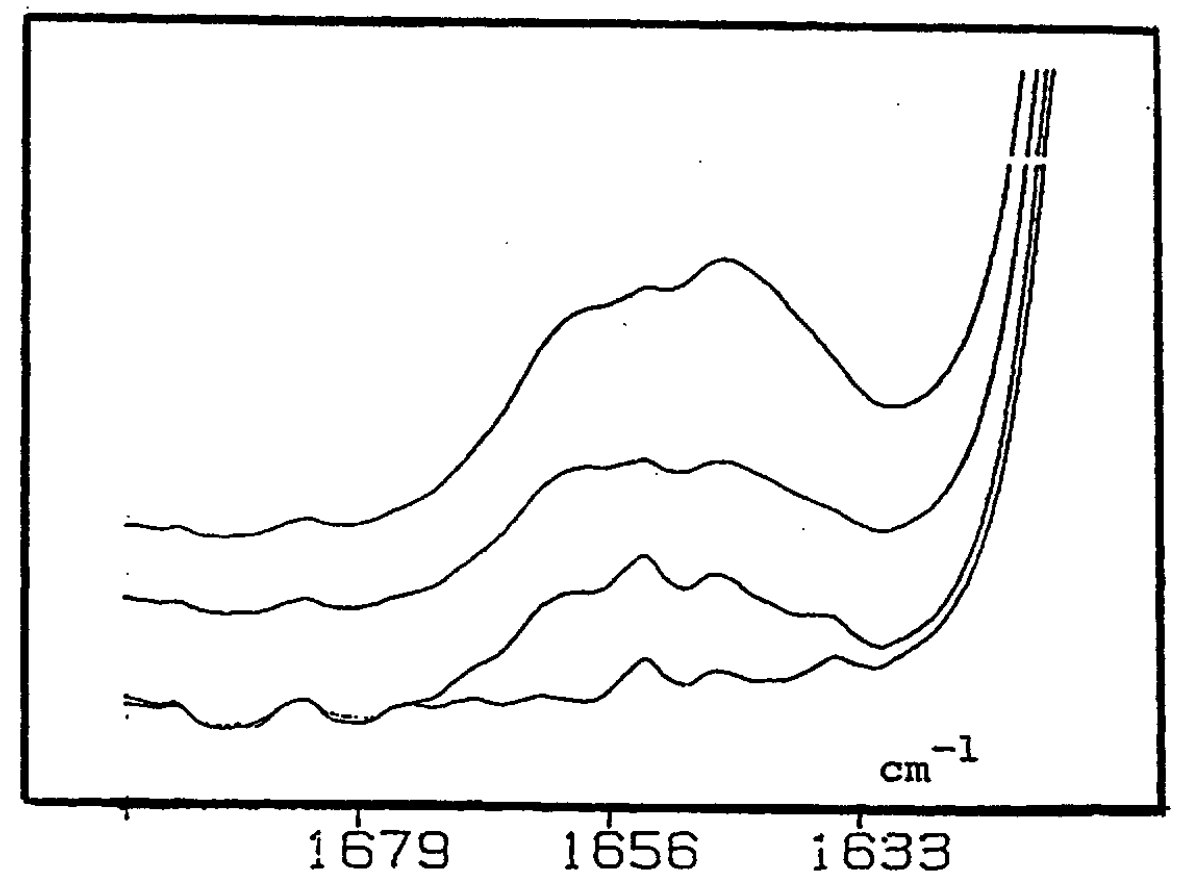

Figure 4. Carbonyl stretching region of the IR spectrum of benzophenone incorporated in films of partially methylated pol(vinylphenol) containing $2,5,15$ and $20 \mathrm{~mol} \%$ of free phenol groups.

The experimentally determined values of $x$ are indicated by the squares in the figure. Although the fit between theory and experiment is by no means perfect, it is close enough to validate the general approach and give some confidence in the calculated values of the fraction of bound inhibitor.

\section{Table IV}

Fraction of bound Benzophenone in Films of Partially Methylated Poly(vinylphenol)

$\mathrm{K}_{\mathrm{A}}=5.0 \quad \mathrm{~K}_{\mathrm{P}}=2.5$

\begin{tabular}{llll}
{$\left[\mathrm{P}_{\mathrm{o}}\right](\mathrm{M})$} & {$[\mathrm{A}]_{\mathrm{o}}(\mathrm{M})$} & $\mathrm{x}$ (calc.) & $\mathrm{x}$ (exper.) \\
\hline 0.08 & 0.011 & 0.26 & 0.28 \\
0.20 & 0.023 & 0.37 & 0.42 \\
0.60 & 0.031 & 0.56 & 0.53 \\
0.84 & 0.050 & 0.61 & 0.58 \\
\hline
\end{tabular}




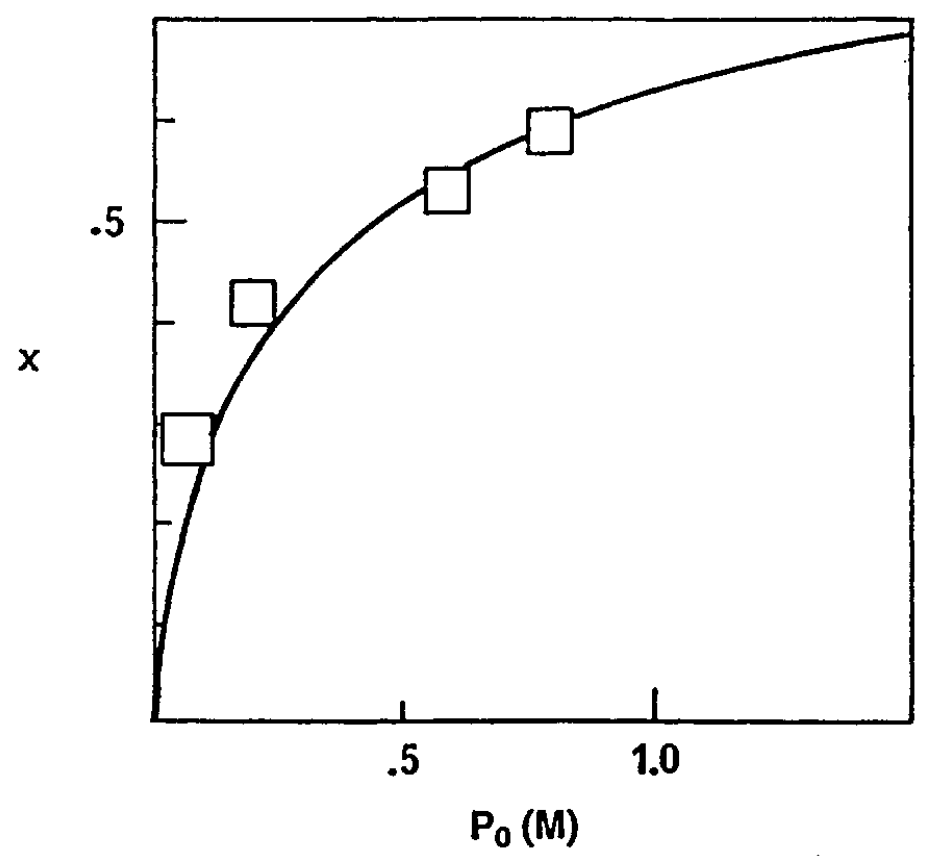

Figure 5. Plot of the phenol-bound fraction of an inhibitor following eq 8, with $\mathrm{K}_{\mathrm{A}}=5.0$, $\mathrm{K}_{\mathrm{p}}=2.5$; the experimentally observed values for benzophenone are indicated by the squares.

Table $\mathrm{V}$

Bound Fraction, $x$, of Acceptor and Inhibition Factor, $\mathrm{f}_{\mathrm{ij}}$

\begin{tabular}{lccc} 
Acceptor & $\mathrm{K}_{\mathbf{A}}$ & $\mathbf{x}$ & $\mathbf{f}_{\mathrm{ij}}$ \\
\hline 1 & 14 & 0.90 & 1.23 \\
2 & 3.2 & 0.67 & 0.88 \\
3 & 2.5 & 0.61 & 0.75 \\
4 & 1.3 & 0.46 & 0.25 \\
5 & 0.6 & 0.28 & 0.00 \\
\hline
\end{tabular}

\section{Correlation between Bound Inhibitor Fraction and Inhibition Effect}

The strength of the inibition effect is often expressed as the inhibition factor $f_{i j}$, defined as the negative slope of a logarithmic plot of dissolution rate against inhibitor concentration, (the so-called Meyerhofer plot). 


$$
\mathrm{f}_{\mathrm{ij}}=\frac{\mathrm{d} \log \mathrm{R}}{\mathrm{dc}_{\mathrm{i}}}
$$

Here $\mathrm{R}$ is the dissolution rate and $\mathrm{c}_{\mathrm{i}}$ the inhibitor concentration (in weight \%). The rate of dissolution of the resists in $0.2 \mathrm{~N} \mathrm{KOH}$ was measured by laser interferometry as described in [4]. The data are listed in Table 4. In Figure 6 we have plotted the inhibition factor of the five inhibitors of Honda's study against the fraction of bound inhibitor calculated by the method described above. There is a clear correlation between the strength of inhibition by an additive and the fraction of its phenol-bound molecules. This result supports the view that the inhibition effect is based on the blocking of phenolic $\mathrm{OH}$-group by an hydrophobic inhibitor, and it shows that the strength of the interaction between phenol and the anchor group of the inhibitor plays a significant role in that process.

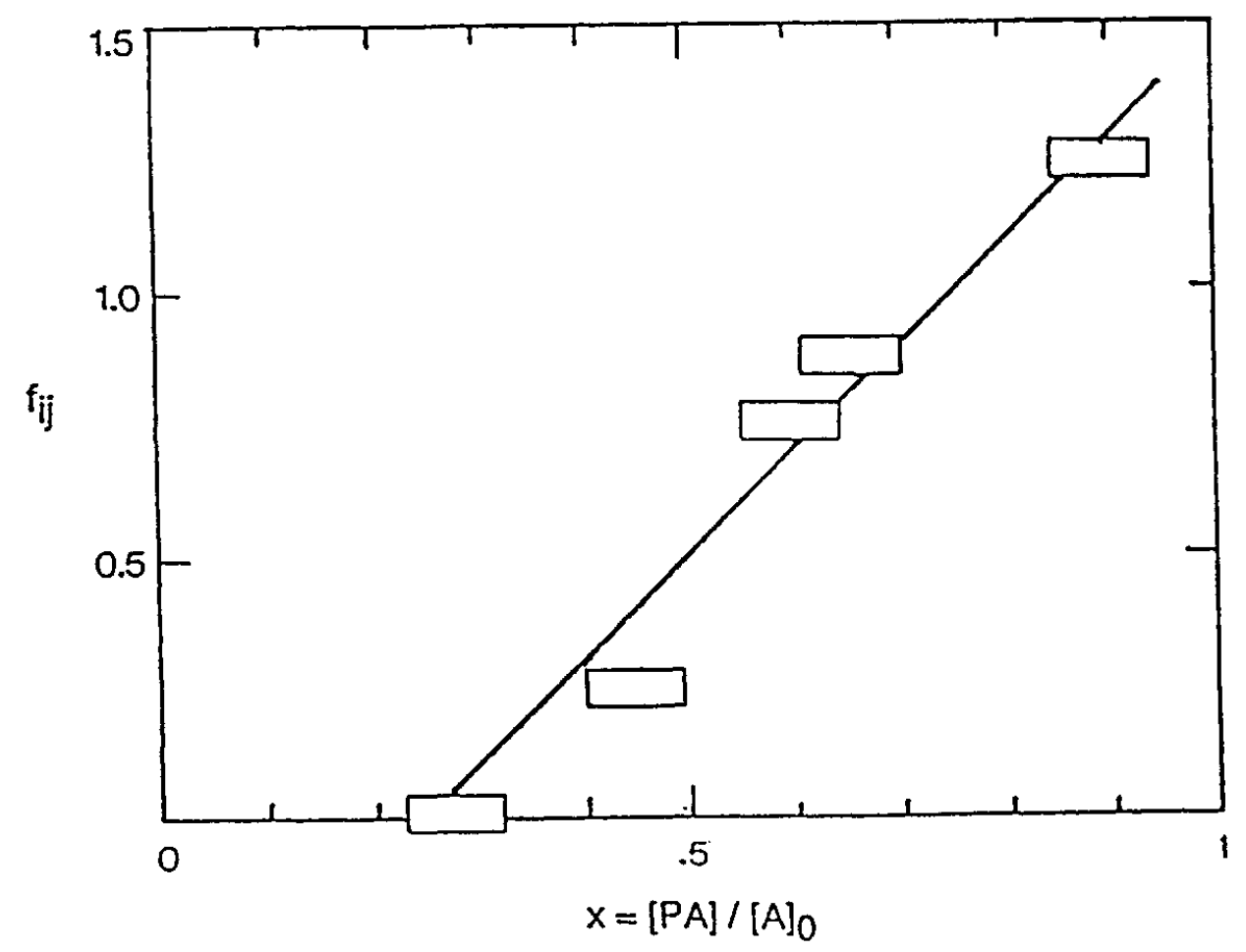

Figure 6. Plot of the inhibition factor $f_{i j}$ against the fraction $x$ of phenol-bound inhibitor. The five inhibitors used in this graph are items 1 to 5 of Scheme $I$. 


\section{Acknowledgement}

C.C. Lin, T.F. Yeh and A. Reiser are grateful for financial support of this work by the Office of Naval Research and by the National Science Foundation.

\section{References}

1. M. Hanabata, Y. Uetani, A. Furuta, Proc. SPIE, 225 (1988), 349.

2. M. Koshiba, M. Murata, M. Matsui, Proc. SPIE, 229 (1988), 364.

3. M. Murata, M. Koshiba, Y. Harita, Proc. SPIE 1086 (1989), 48.

4. T.F. Yeh, H.Y. Shih, A. Reiser, Proc. SPIE 1672 (1992), 204. and Macromolecules, 25 (1992), 5345.

5. K. Honda, B.T. Beauchemin, R.J. Hurditch, A.J. Blakeney, Y. Kawabe, T. Kokubo Proc. SPIE 1262 (1990), 493.

6. K. Honda, B.T. Beauchemin, E.A. Fitzgerald, A.T. Jeffries, S.P. Tadros, A.J. Blakeney, R.J. Hurditch, S. Tan, and S. Sagakuchi, Proc. SPIE 1466 (1991), 141. 